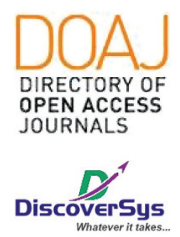

Published by DiscoverSys

\section{Culture results on chest tube thoracostomy water- sealed drainage in patients with pneumothorax at Sanglah General Hospital, Bali-Indonesia}

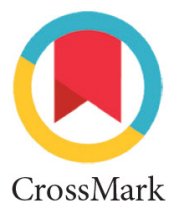

\author{
Putu Bagus Anggaraditya ${ }^{1 *}$, Arland Chandra ${ }^{2}$
}

\title{
ABSTRACT
}

Introduction: Thoracic trauma is one type of trauma with a high incidence that causes morbidity and mortality after head trauma and extremity. The act of installing a thoracostomy has become one of the standard management of thoracic injury. Infection is a complication that can occur during treatment. This study aimed to provide an overview of the results of thoracostomy tube watersealed drainage (WSD) culture in pneumothorax patients at Sanglah Hospital.

Method: The study design used a cross sectional descriptive method. The subjects of the study were blunt thoracic trauma patients with pneumothorax who came to the emergency department of Sanglah Hospital to indicate the installation of a thoracostomy hose during the period January to December 2018. Results: From 40 study samples there were 32 subjects with positive culture results, then from all subjects with positive culture results found 10 people (25\%) with culture results of staphylococcal aureus bacteria, based on rib fractures more samples with rib fractures less than two bones ( $62.5 \%$ ), based on the duration of WSD installation there were more samples with the duration of WSD installation more than 7 days (75\%).

Conclusion: The high positive culture results which are dominated by pyogenic skin bacteria, namely Stapylokokus aureus is a challenge for surgeons in managing the complications of tube thoracostomy (TT) installation in patients with pneumothorax.

Keywords: pneumothorax, infection, complication, tube

Cite This Article: Anggaraditya, P.B., Chandra, A. 2019. Culture results on chest tube thoracostomy water-sealed drainage in patients with pneumothorax at Sanglah General Hospital, Bali-Indonesia. Intisari Sains Medis 10 (1): 188-191. D0I: 10.1556/ism.v10i1.431

${ }^{1}$ Emergency Department, Sanglah General Hospital, Sanur, BaliIndonesia

${ }^{2}$ Post Graduate Surgery Resident, Faculty of Medicine, Udayana University-Sanglah General Hospital, Bali-Indonesia

\section{*Corresponding: Putu Bagus Anggaraditya; Emergency Department, Sanglah General Hospital, Sanur, Bali- Indonesia; putubagusanggaraditya@gmail. com}

Received: 2019-03-08 Accepted: 2019-03-24 Published: 2019-04-01

\section{INTRODUCTION}

The increasing number of motorized vehicles as a means of commercial transportation in developing countries has indirectly increased the incidence of thoracic trauma, especially in the productive age. The impact of traffic accidents that occur makes thoracic injury one of the public health problems in several countries.

Thoracic trauma is trauma that affects the thoracic wall and directly affect the internal organs. ${ }^{1,2}$ Based on the causes of trauma divided into blunt and sharp trauma with the highest number of incidents is blunt trauma.

Thoracic trauma is one of the injuries with a high incidence that causes morbidity and mortality after head trauma and extremities. ${ }^{3}$ More than 16,000 deaths each year or 20 to 25 percent of all trauma events occur in the United States.

Pneumothorax and hemothorax are the most common complications in the pleural cavity due to blunt thoracic trauma. ${ }^{2,4}$ In South Africa blunt chest trauma has a high incidence of more than 45 percent of all trauma and has a high mortality rate due to late treatment. 5
Pneumothorax due to blunt thoracic trauma is the presence of air in the pleural cavity due to visceral pleural tear or alveolar rupture due to a sharp fragment of the rib bone from a rib fracture or heavy compression that suddenly occurs on the thoracic wall. ${ }^{1}$

Management of pneumothorax must be done immediately after the diagnosis is made because it can develop into a tension pneumothorax that has a high mortality rate. ${ }^{6}$ Management is life-saving with the installation of a tube thoracostomy (TT). ${ }^{7}$

The act of mounting TT was first published by Hewett in 1876 by draining empyema. During World War II and the Vietnam war it developed into a standard of management of thoracic trauma in public and military hospitals. ${ }^{8}$ Installation of TT has complications during installation, during treatment or after revocation of TT.

TT is still an invasive procedure and has a lot of potentials to experience a complication. Complications that occur are related to installation and infection. In a study conducted by Collop et al. out of 126 patients who underwent the TT procedure, found that there were complications of advanced infection in the form of thoracic 
empyema which required thoracotomy. ${ }^{9}$ While the case reports reported by Hsu et al. ${ }^{10}$ illustrates that there is a possible risk of necrotizing fasciitis as a further complication of TT installation. This description demonstrates that there are many problems related to early complications and further complications from TT insertion, this study aims to provide an overview of the culture results from TT insertion and give an overview of microbial patterns as a cause of infectious complications from TT insertion at Sanglah General Hospital in patients with pneumothorax.

\section{METHOD}

This research is a cross-sectional descriptive study. This research was conducted in the Emergency Room and inpatient ward of the Sanglah General Hospital Denpasar. The sample in this study was patients with blunt thoracic trauma and experiencing pneumothorax who needed the action of tube thoracostomy insertion. The diagnosis of pneumothorax is made through history, physical examination, and chest radiology. The installation of the thoracostomy tube is carried out in accordance with the standard protocol in the acute trauma live support guide (ATLS) with tubes various type of chest tube size $28 \mathrm{Fr}, 32 \mathrm{Fr}$ and $36 \mathrm{Fr}$ in adults and $16 \mathrm{Fr}, 20 \mathrm{Fr}$ and $24 \mathrm{Fr}$ in children, after the installed, tube is connected with a disposable water seal drainage container with pressure suction of $20 \mathrm{cmH}_{2} 0$.

Close monitoring of patients is carried out for two days, observed until the extraction of the TT WSD is carried out and retrieval of specimens at the end of the hose. Samples will be delivered through the cooling box in 40 minutes to the microbiology laboratory. From each container five preparations will be made with dilutions 10 times to 10,000 times. Germ culture techniques are adapted to the standard Microbiology protocol of Sanglah General Hospital Denpasar. The results of TT culture were said to be positive if bacterial growth was found on the TT end with colony growth $>15$ colonies. Statistical analysis using SPSS version 20.0 software for Windows, data is analyzed descriptively and then displayed in table form

\section{RESULT}

Characteristics of respondents were presented based on age, gender, treatment is given, type of germs and duration of use of WSD presented in Table 1.
Table 1. Frequency distribution of characteristics of research subjects

\begin{tabular}{lc}
\hline \multicolumn{1}{c}{ Variable } & N (\%) \\
\hline Age & \\
$\geq 42$ years & $24(60 \%)$ \\
$<42$ years & $16(40 \%)$ \\
Gender & \\
Male & $26(65 \%)$ \\
Female & $14(35 \%)$ \\
Number of rib fracture & \\
$\leq 2$ bone & $25(62.5 \%)$ \\
$>2$ bone & $15(37.5 \%)$ \\
WSD duration & \\
$\geq 7$ day & $30(75 \%)$ \\
$<7$ day & $10(25 \%)$ \\
Microbial agent culture & \\
Staphylococcus sp & $10(25 \%)$ \\
Pseudomonas sp & $4(10 \%)$ \\
Streptococcus sp & $3(7.5 \%)$ \\
Acitenobacter & $4(10 \%)$ \\
Enterobacter sp & $9(22.5 \%)$ \\
Klebsiella sp & $2(5 \%)$ \\
Gram negative bacteria & $8(20 \%)$ \\
Culture result & \\
Positive result & \\
Negative result & $32(80 \%)$ \\
\hline
\end{tabular}

In this study, the median age variable was 42 years and the median duration of using WSD was 7 days. The majority of subjects aged less than 42 years $(60 \%)$, male sex $(65 \%)$, experienced $<2$ bone fractures as many as 25 respondents $(62.5 \%)$, WSD use $\geq 7$ days ( $75 \%$ ), and three types the most isolated germs are Staphylococci sp (25\%), Enterobacter sp (22.5\%), Acinetobacter (10\%) (Table 1).

\section{DISCUSSION}

In this study $80 \%$ of the culture results showed a positive result in bacterial detection, then the most bacteria found were Staphylococcus sp. with a proportion of $25 \%$. Research conducted by Brims et al. ${ }^{11}$ in 713 patients who were paired with TT in Australia, there were 36 patients who had complications of pleural infection after TT administration, in terms of bacteriological findings found the most germs were Staphylococcus Aureus in 12 subjects, viridans streptococci in 9 subjects, Streptococcus milleri in 7 subjects, Klebsiella pneumoniae in 3 subjects, and Pseudomonas spp in 5 subjects. This shows that there are similar findings on the results of bacteriological evaluations which indicate that the streptococcal variant bacteria are the most findings obtained from the results of these cultures. 
Another study conducted by Fysh et al. ${ }^{12} 2013$ in 1021 patients who underwent TT heating, found 50 patients who had complications of pleural infection within 62 days. Based on germ culture carried out found 24 (48\%) people who had an infection of Staphylococcus aureus, then other gram-positive bacteria such as Staphylococcus epidermidis, Corynebacterium G, Propionibacterium acnes, Streptococcus viridans which covered $14 \%$ of all gram-positive bacterial culture results. Then the gram-negative bacteria $18 \%$ of the total includes Pseudomonas aeruginosa, Escherichia coli, Enterobacter cloacae, Enterococcus faecalis, Klebsiella pneumonia, Klebsiella oxytoca.

Pleural infection can be defined as a progressive process, where a focus of parapneumonic effusion can increase its progression into a multi-loculated fibrotic collection that requires surgical intervention. This is formed when there is an entrance from the outside of the body to the pleural space, this will increase the visceral pleural permeability and leakage from the interstitial fluid in response to inflammation. With migration of neutrophil together with the release of proinflammatory cytokines such as IL-6, IL-8, and tumor necrosis factor alpha (TNF- $\alpha$ ), the results cause an intracellular gap between the pleura and mesothelial cells resulting in accumulation of pleural fluid. During this exudative period the liquid generated is not so complex and tends to show no microbiological agents or significant biochemical changes. ${ }^{13}$

The reason for the invasion of secondary bacteria in the pleural space is still not well understood. However, there is a hypothesis that bacteria are infections through the percutaneous (skin) route. This also explains why the most common bacterial findings are Staphylococcus aureus that is a common pyogenic skin bacteria. Infection that occurs causes several changes in the pleural space, this causes changes in biochemical characteristics. The presence of bacterial metabolism and phagocytosis of neutrophils causes an increase in production of lactic acid and carbon dioxide, causing changes in $\mathrm{pH}$ and glucose concentration from the pleura which can be used as a marker of pleural infection. The continued release of inflammatory cytokines such as IL-9, TNF- $\alpha$, vascular endothelial growth factor (VEGF), and monocyte chemotactic production (MCP) will further increase pleural fluid production. This event is accompanied by a decrease in the level of fibrinolysis inhibitors such as plasminogen activity inhibitors (PAI). The reduction in fibrinolysis activity causes deposition of fibrin which covers the part of the visceral and parietal pleura and divides it into two different pockets. The result of this condition is purulent fluid (empyema) which is composed of bacteria, dead leukocyte cells, and cellular debris. ${ }^{14,15}$

\section{CONCLUSION}

Through tracing thoracostomy tube culture, $80 \%$ of the samples had positive culture results, and the most bacteria found were Staphylococcus aureus. Based on the number of rib fractures, more samples with fewer rib fractures than two bones. The result of culture as a marker of infection from the pleura is a challenge for surgeons in carrying out management from complications due to the installation of TT.

\section{CONFLICT OF INTEREST}

The author declares there is no conflict of interest regarding all elements in this study

\section{FUNDING}

Current study doesn't receive any specific grant from government or any private sector.

\section{REFERENCES}

1. Lugo VW, et al. Chest Trauma: An Overview. Journal of Anesthesia \& Critical Care. 2015;3(1):1-11.

2. Guitron J, Huffman LC, Howinton JA, LoCicero J. Blunt and penetrating injuries of the chest wall, pleura and lungs. In: Shields TW, LoCicero J, Reed CE, Feins RH, eds. General Thoracic Surgery. Seventh Edition. Philadelphia: Lippincott Williams \& Wilkins. 2009. p. 891-902.

3. Eckstein M, Handerson SO. Rosen's Emergency Medicine Concepts and Clinical Practice. 8th ed. Philadelphia: Elsevier Saunders. 2014.

4. Clark D and Fantus R. National Trauma Data Bank, American College of Surgeons Annual Report. American College of Surgeons. 2007;6(2):61-64.

5. Mefire AC, et al. Analysis of epidemiology, lesions, treatment and outcome of 354 consecutive cases of blunt and penetrating trauma tothe chest in an African setting. South African Journal Of Surgery. 2010;7(2):90-93.

6. Brims FJH, Maskell NA. Ambulatory treatment in the management of pneumothorax: a systematic review of the literature. Thorax. 2013;68:664-669.

7. Kuhajda I, et al. Review Article: Tube thoracostomy; chest tube implantation and follow up. J Thorac Dis. 2014;6(S4):S470-S479.

8. Hewett FC. Thoracentesis: the plan of continuous aspiration, The British Medical Journal. 1876;17(9):317-321. 
9. Collop NA, Kim S, Sahn SA. Analysis of tube thoracostomy performed by pulmonologist at a teaching hospital. CHEST. 1997;112:703-13.

10. Hsu SP, Wang HC, Huang IT, Chu KA, Chang HC. Tube thoracostomy-related necrotizing fasciitis: a case report. Kaohsiung J Med Sci. 2006;22:636-40.

11. Brims F, Rosentengal A, Yogendran, et al. The bacteriology of pleural infection in western Australia. Am J Respir Crit Care Med. 2014;189:A5427.

12. Fysh ETH, Tremblay A, Kopman DF, Mishra EK, Slade M, Garske L, et al. Clinical outcomes of indwelling pleural catheter-related pleural infection. CHEST. 2013;144(5):1597-1602.

13. Corcoran JP, Wrighston JM, Belcher E, DeChamp MM, Kopman DF, Rahman NM.
Pleural infection: past present, and future direction. The Lancet. 2015;3:563-577.

14. Seville R, Riha RL, Rahman N. Pleural infection. Respiratory Medicine CME. 2009;2:107-110.

15. Sukrama DM, Wihandani DM, Manuaba AM. Topical binahong (Anredera cordifolia) leaf extract increase inteleukin-6 and VEGF (vascular endothelial growth factor) during burn wound healing in wistar rats infected with pseudomonas aureginosa. Biol Med (Aligarth). 2017;9(1):369. DOI: 10.4172/09748369.1000369 .

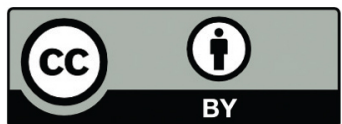

This work is licensed under a Creative Commons Attribution 